\title{
Optimetric analysis of 1x4 array of circular microwave patch antennas for mammographic applications using adaptive gradient descent algorithm
}

\author{
Ojo O. Adedayo, Moses Oluwafemi Onibonoje, Ogunlade Michael Adegoke \\ Department of Electrical Electronic and Computer Engineering, College of Engineering, \\ Afe Babalola University Ado Ekiti (ABUAD), Nigeria
}

\begin{tabular}{l} 
Article Info \\
\hline Article history: \\
Received Feb 25, 2019 \\
Revised Apr 4, 2019 \\
Accepted Jun 2, 2019 \\
\hline
\end{tabular}

Keywords:

Breast imaging

Gradient descent algorithm

HFSS

Neural network

Patch antenna

\begin{abstract}
Interest in the use of microwave equipment for breast imagery is on the increase owing to its safety, ease of use and friendlier cost. However, some of the pertinent blights of the design and optimization of microwave antenna include intensive consumption of computing resources, high price of software acquisition and very large optimization time. This paper therefore attempts to address these concerns by devising a rapid means of designing and optimizing the performance of a $1 \times 4$ array of circular microwave patch antenna for breast imagery applications by deploying the adaptive gradient descent algorithm (AGDA) for a circumspectly designed artificial neural network. In order to cross validate the findings of this work, the results obtained using the adaptive gradient descent algorithm was compared with those obtained with the deployment of the much reported LevenbergMarquardt algorithm for the same dataset over same frequency range and training constraints. Analysis of the performance of the AGDA neural network shows that the approach is a viable and accurate technique for rapid design and analysis of arrays of circular microwave patch antenna for breast imaging.
\end{abstract}

Copyright (c) 2019 Institute of Advanced Engineering and Science. All rights reserved.

\section{Corresponding Author:}

Ojo O. Adedayo,

Departement of Electrical Electronic and Computer Engineering,

Afe Babalola University Ado-Ekiti (ABUAD),

PMB 5454, Km 8.5, Afe Babalola Way, Ado Ekiti, Ekiti State Nigeria.

Email: ojoao@abuad.edu.ng

\section{INTRODUCTION}

Maxwell's set of electromagnetic equations have been the main way to obtain accurate and reliable solutions for electromagnetic radiation pattern problems before the advent and development of computerbased simulation software. This software design approach helps a great deal in simplifying otherwise complex equations and conditions upon which solutions for the behaviour of radiation patterns of complex structures are based. Using suitable optimization techniques, these computer-aided simulations have opened the research world into interesting unending possibilities in terms of structural designs leading into the design of state of the art microwave components and devices that include filters, resonators and antennas [1, 2]. Results from this development have been employed in making life much easier as they have been deployed for medical applications as in the case of medical imaging [3], noninvasive tomography [4] and cancer detection [3-8].

The major challenges facing the computer aided simulations of high frequency structures however include the requirement of large amount of computing resources. This is often because multi-objective optimization of electric and magnetic field patterns and distributions around complex structures often require a great deal of iterations and analysis. As a result, the quest for the development of accurate, rapid and less 
computationally intensive approaches for the design and performance analysis of microwave structures remains relatable. To this end, softcomputing techniques have come as a handy solution.

Artificial Neural Networks (ANNs) in particular have been of great use in this regard, wherein their versatility, computational ease, speed and excellent capacity in solving non-linear problems have been exploited for the design of microwave devices. Efforts in this domain include the development of ANN based techniques for the characterization of organic tissues using microwave antennas [9, 10]. Similar successful ANN-based works that are even more relatable to the domain of this paper include [11, 12] where in the performances of cancer detecting microwave antennas were improved using the computing prowess of massively connected computing artificial nodes.

The performance of ANNs is nevertheless dependent on the network architecture as well as the efficiency of the training algorithm employed. This work therefore explores the efficiency of the adaptive gradient descent algorithm for the optimetric and performance analysis of a $1 \times 4$ array of circular microwave antenna for mammographic applications.

\section{RESEARCH METHOD}

The procedure involved in this work includes the design and simulation of the antenna array as well as the breast tissue prototype. An adaptive gradient descent algorithm was then deployed on an Artificial Neural Network with the aim of accurately and sufficiently modeling the electromagnetic problem.

\subsection{The antenna array}

The physical configuration of the antenna consists of a $1 \times 4$ array of circular patch antenna as shown in Figure 1 which were optimized to obtain the gain and power suitable for breast imagery and other microwave mammographic applications. At a sweep frequency range of $1 \mathrm{GHz}$ to $5 \mathrm{GHz}$, the antenna radiation pattern was obtained and the parameter optimization was carried out in order to acquire the electric field and magnetic field distribution of the antenna array. This information, together with the current density distribution data can then be used for antenna calibration and characterization of the human breast tissue under regulated power and frequency. The properties and dimensions of various components and subsections of the antenna are listed in Table 1.

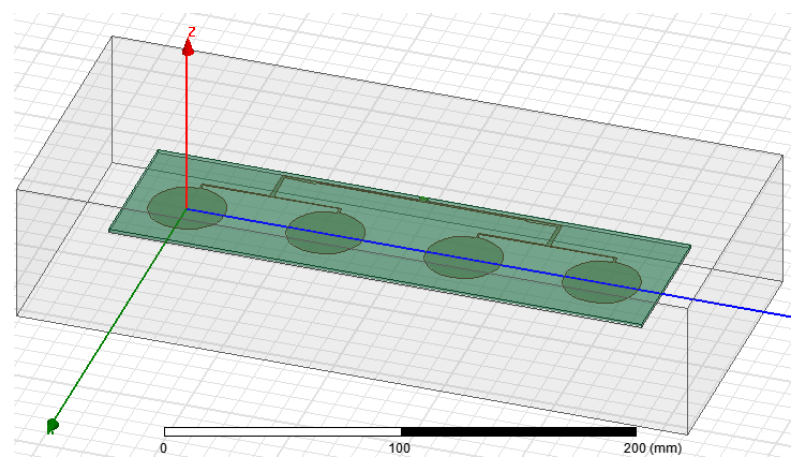

Figure 1. Structure of the antenna array

Table 1. Dimensions and properties of various components of the design

\begin{tabular}{|c|c|c|c|c|c|c|}
\hline \multirow[t]{2}{*}{ MATERIAL } & \multicolumn{4}{|c|}{ PROPERTIES } & \multirow[t]{2}{*}{ COMPONENT } & \multirow{2}{*}{$\begin{array}{c}\text { DIMENSION/ } \\
\text { LOCATION } \\
(\mathrm{mm})\end{array}$} \\
\hline & $\begin{array}{l}\text { Relative } \\
\text { Permittivity }\end{array}$ & $\begin{array}{c}\text { Relative } \\
\text { Permeability }\end{array}$ & Bulk Conductivity & Mass Density & & \\
\hline FR4_epoxy & 4.4 & 1 & 0 & 1900 & Substrate & $\begin{array}{c}X=-67.075 \\
Y=-240.7 \\
Z=1.6\end{array}$ \\
\hline Vacuum & 1 & 1 & 0 & 0 & Radiation Box & $\begin{array}{c}X=-129.575 \\
Y=-303.2 \\
Z=-64.1\end{array}$ \\
\hline $\begin{array}{l}\text { Copper } \\
\text { Sheets }\end{array}$ & 1 & 0.999991 & 58000000 Siemens/m & 8933 & Source & $\begin{array}{c}X-\text { Axis } \\
Y=-3 \\
Z=-1.6\end{array}$ \\
\hline & 1 & 0.999991 & 58000000 Siemens/m & 8933 & Patch & Radius - 17 \\
\hline & 1 & 0.999991 & 58000000 Siemens/m & 8933 & Ground & $\begin{array}{c}Z-\text { Axis } \\
X=-67.075 \\
Y=-240.7\end{array}$ \\
\hline
\end{tabular}




\subsection{Adaptive gradient descent algorithm (AGDA)}

The overall aim of Gradient Descent Algorithm is to reduce the error function, E opposite to the direction to the error gradient in order to successively approach the minimum achievable error function [13]. The Gradient Descent Algorithm showing the direction of the error gradient and the minima with respect to layer weights $\mathrm{Wi}$ and $\mathrm{Wj}$ is illustrated on a surface plot and shown in Figure 2.

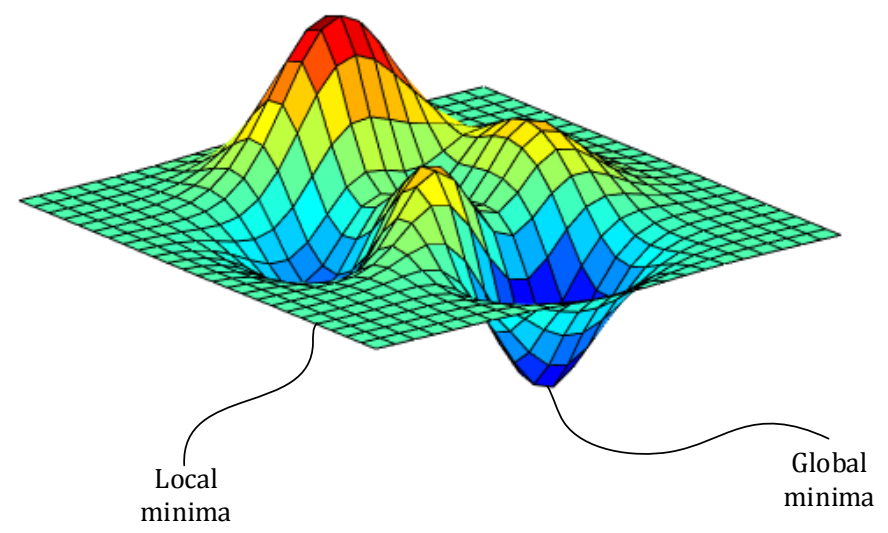

Figure 2. Illustration of the gradient descent error surface

The change in the error function with respect to the network weights is written as:

$$
G_{d}=\frac{\partial E}{\partial w_{i j}^{2}}
$$

Where $w_{i j}^{2}$ is the connecting weight from the hidden layer to the output layer. This can also be re-written as:

$$
\begin{aligned}
& G_{d}=\frac{\partial E}{\partial w_{i j}^{2}}=\frac{\partial E}{\partial O_{i}^{2}} \times \frac{\partial O_{i}^{2}}{\partial w_{i j}^{2}} \\
& \frac{\partial E}{\partial O_{i}^{2}}=-\left(t_{j}-O_{i}^{2}\right)
\end{aligned}
$$

Also, the network output $O_{i}^{2}$ is expressed as:

$$
O_{i}^{2}=\sum_{i} w_{i j}^{2} p_{i}
$$

Therefore,

$$
\begin{gathered}
\frac{\partial O_{i}^{2}}{\partial w_{i j}^{2}}=\frac{\partial}{\partial w_{i j}^{2}} \sum_{i} w_{i j}^{2} p_{i}=p_{i} \\
G_{d}=\frac{\partial E}{\partial w_{i j}^{2}}=-\left(t_{i}-O_{i}^{2}\right) p_{i}
\end{gathered}
$$

To arrive at a global solution, the weight correction must oppose the direction of the error gradient; the change in weight can thus be written as:

$$
\Delta w_{i j}^{2}=\left(t_{i}-O_{i}^{2}\right) p_{i}
$$

Consequently, the new weight is expressed as:

$$
w^{2}{ }_{i j_{\text {new }}}=w^{2}{ }_{i j_{\text {old }}}+\Delta w_{i j}^{2}=w^{2}{ }_{i j_{\text {old }}}+\alpha\left(t_{i}-O_{i}^{2}\right) p_{i}
$$


In summary, AGDA is an ANN training algorithm that adapts the value of its learning rate, weight and bias as informed by gradient descent. The initial error and output of the network are first computed for each epoch, and the new biases, outputs and weights are computed with the current learning rate. The algorithm requires that if the newly computed error is greater than the previous error by more than a set value $\varrho$, the new biases and weights are discarded and the learning rate is reduced by a factor $\Delta \mathrm{L}_{\mathrm{r}}$ else, the new parameters are retained. In this way, a set of network weights and biases are obtained which yields the output with the closest values to the target for the problem terrain. For this work the values of $\varrho$ and $\Delta \mathrm{L}_{\mathrm{r}}$ are 1.04 and 0.7 respectively. These values were selected after rigorous trial and error process for optimum performance of the algorithm.

\subsection{The neural network architecture}

The architecture of the artificial neural network consists of three input layer neurons and one output layer neuron. The total number of hidden layer neurons were varied in steps between 10 and 40 neurons and the corresponding performances of the networks were evaluated with both adaptive gradient descent (AGD) and Levenberg-Marquardt algorithms. The results of this procedure are presented in Table 4. In each case, the inputs of the network consist of the radius (R), in millimeter, of the circular elements of the antenna array, the centre-to-centre (CTC) spacing of the circular elements of the antenna array in millimeter, and the frequency (F) in Gigahertz. The training data was obtained from robust and intensive optimetric simulation and performance optimization on High Frequency Structure Simulation (HFSS) software. The training dataset, made up of 800 datapoints was divided randomly into three parts, one part which is $70 \%$ of the data was used for the training, another part which is $15 \%$ was deployed for the validation and the last part for the testing. The use of this particular ratio was to ensure that the network was trained with sufficient data in order to achieve good generalization performance as well as to avoid overtraining.

\section{RESULTS AND ANALYSIS}

The radiation pattern and performance of the $1 \times 4$ circular antenna array were evaluated from a frequency range between $1 \mathrm{GHz}$ and $5 \mathrm{GHz}$. The results in terms of centre frequency, structural configuration, frequency range, and gain are compared against similar results in literature in same domain. The results of this comparison are presented in Table 2. Our optimized antenna array performed quite satisfactorily as evidenced by its gain of $8.46 \mathrm{dBi}$ which is $24.41 \%$ higher than the highest gain of antenna structures cross-compared. This improved property is a good quality for microwave antennas especially as it enhances the resolution and precision when the antenna is deployed for breast imagery and other mammographic applications.

Table 2. Comparison of the performances of breast imaging/cancer detection antennas

\begin{tabular}{ccccc}
\hline Centre frequency $(\mathrm{GHz})$ & Structure & Frequency range $(\mathrm{GHz})$ & Gain $(\mathrm{dBi})$ & Ref \\
\hline 12 & Cylindrical slotted patch antenna & $0-20$ & 6.40 & {$[14]$} \\
2.45 & Rectangular patch antenna with insert gap & $-\overline{-20}$ & $\overline{2.98}$ & {$[3]$} \\
14.26 & Square patch antenna with T-slot in ground plane & $5-10$ & 6.80 & {$[5]$} \\
5.5 & Proximity fed V-slot patch antenna & $0-5$ & 8.46 & This work \\
2.45 & 1X4 circular patch antenna array & 0.50 & \\
\hline
\end{tabular}

During the optimization procedure on HFSS, the centre-to-centre (CTC) distance of the four elements of the antenna array was varied from $60 \mathrm{~mm}$ to $65 \mathrm{~mm}$ and the radius $\mathrm{R}$ of the array elements was varied from $10 \mathrm{~mm}$ to $20 \mathrm{~mm}$. The S-parameter and the voltage standing wave ratio were also evaluated for all possible combinations of the two variables within the individual ranges. A few of these results are presented in Figure 3(a) and the radiation pattern is shown in Figure 3(b).

The performance of the artificial neural network presented in this work (already described in Section 2.3) in response to the testing data inputs was evaluated using three major performance evaluation criteria: the root mean square error (RMSE), the variance account-for (VAF) and the coefficient of multiple determination (CMD). These procedures were executed for the network for both the AGD and the Levenberg-Marquardt algorithms and the results are presented in Table 3. 


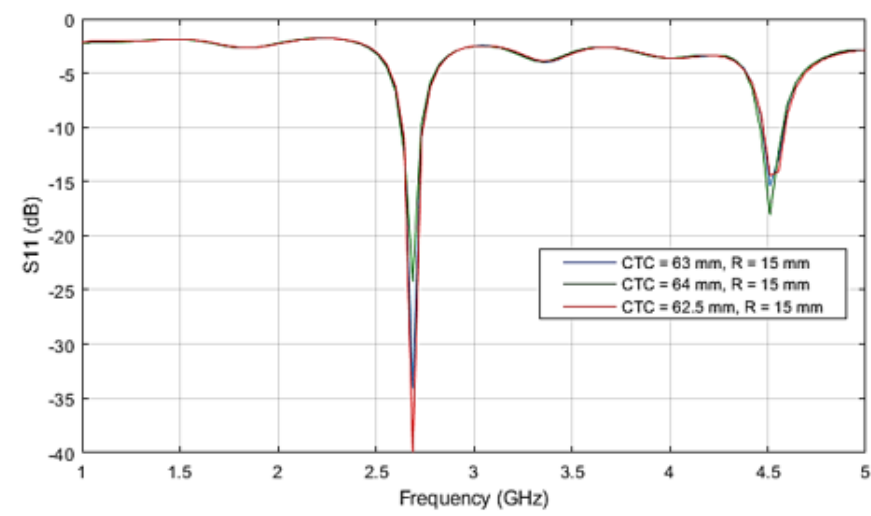

(a)

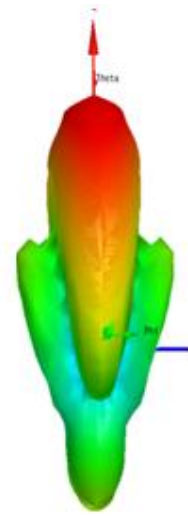

(b)

Figure 3. The result of the HFSS optimization procedure showing, (a) the S-parameter, and (b) the radiation pattern of the antenna

Table 3. Performance indices of the algorithms for the training, validation and testing data

\begin{tabular}{|c|c|c|c|c|c|}
\hline \multirow{2}{*}{ Network } & \multicolumn{2}{|c|}{ Training } & \multicolumn{3}{|c|}{ Testing } \\
\hline & Training VAF & Validation VAF & CMD & VAF & RMSE \\
\hline AGDA_ANN & 96.11 & 97.23 & 0.9666 & 94.81 & 3.98 \\
\hline LM_ANNN & 97.64 & 97.07 & 0.9874 & 93.75 & 4.77 \\
\hline
\end{tabular}

It can be observed that, in comparison with the Levenberg-Marquardt algorithm (LM-ANN), the AGD algorithm performed satisfactorily for both the training, validation and testing data wherein it attained VAF of at least 94.81 and a maximum VAF of 97.23 for the validation data. Even though the LMANN performed better than the AGDA for the training VAF for example, the AGDA still outperformed the LM_ANN for the testing RMSE and validation VAF. This behaviour is an indication that, depending on the data distribution and data structure, ANN training algorithms are well suited to different problems than the other, and that the AGDA is well suited to the microwave antenna array problem at hand.

Varying the number of hidden layer neurons of the network yielded different ANN architectures with varying performances. The two best performing networks from this modification are presented in Table 4. Network A has 32 hidden neurons while Network B has 28 hidden neurons.

Table 4. Performances of different ANN architectures using AGDA

\begin{tabular}{ccccc}
\hline $\begin{array}{c}\text { Network } \\
\text { type }\end{array}$ & $\begin{array}{c}\text { VAF values for training } \\
\text { data }(\%)\end{array}$ & $\begin{array}{c}\text { CMD values for training } \\
\text { data }\end{array}$ & $\begin{array}{c}\text { VAF values for testing } \\
\text { data }(\%)\end{array}$ & $\begin{array}{c}\text { CMD values for } \\
\text { testing data }\end{array}$ \\
\hline Network A & 97.23 & 0.9176 & 94.81 & 0.9666 \\
Network B & 97.52 & 0.9006 & 94.01 & 0.9341 \\
\hline
\end{tabular}

Results from this paper have shown that the performance of neural network based algorithm is largely based on a number of other factors more than the sheer efficiency of the flow of the algorithm itself. These factors include the neural network architecture, the distribution of the data that defines the problem at hand as well as the weight initialization, choice of the learning rate and the adaptation thereof.

\section{CONCLUSION}

In this work, the challenges associated with the development of rapid, cheap and efficient models which are applicable for noninvasive microwave characterization, modelling and imaging of the human breast was addressed as a 1x4 circular antenna array operating at an optimal frequency of $2.45 \mathrm{GHz}$ was designed and analysed for breast imaging applications using the optimization approach offered by the high frequency structure simulator (HFSS) software, a 3D model of the human breast and carefully designed artificial neural network. The ANN results when compared with the simulated data using three different performance indices yielded high accuracy and impressive generalization ability. This therefore indicates that this approach remains a promising one in the domain of noninvasive breast imagery and general mammographic imaging solutions. 


\section{REFERENCES}

[1] S. J. Chin, M. Z. A. A. Aziz, and M. R. Ahmad, "Microstrip-Fed Circular Disc Monopole Antenna with Defected Waveguide Structure," International Journal of Electrical and Computer Engineering (IJECE), vol. 8, no. 1, pp. 189-197, 2018.

[2] M. Tarbouch, A. El Amri, and H. Terchoune, "Design, Realization and Measurements of Compact Dual-band CPW-fed Patch Antenna for 2.45/5.80 GHz RFID Applications," International Journal of Electrical and Computer Engineering (IJECE), vol. 8, no. 1, pp. 172-178, 2018.

[3] R. Çal, S. S. Gültekin, D. Uzer, and Ö. Dündar, "A Microstrip Patch Antenna Design for Breast Cancer Detection," Procedia Soc. Behav. Sci., vol. 195, pp. 2905-2911, 2015.

[4] K. Ouerghi, N. Fadlallah, A. Smida, R. Ghayoula, J. Fattahi, and N. Boulejfen, "Circular Antenna Array Design for Breast Cancer Detection,” Sensors Networks Smart Emerg. Technol., no. 1, pp. 3-6, 2017.

[5] M. Khan, at al., "UWB L-Probe Proximity Fed V-Slot Patch Antenna for Early Detection of Breast Cancer," IEEE Int. Symp. Antennas Propag. Usn. Natl. Radio Sci. Meet., pp. 1882-1883, 2015.

[6] T. Shah and E. Siores, Wearable microwave radiometry device for early detection of sub-tissue oncological imperfections, Woodhead Publ. Ltd., pp. 437-448, 2010.

[7] A. Afyf, L. Bellarbi, N. Yaakoubi, E. Gaviot, L. Camberlein, and M. Latrach, "Novel Antenna Structure for Early Breast Cancer Detection,” Procedia Eng., vol. 168, pp. 1334-1337, 2016.

[8] T. Hirano, at al.,"4 x 4 Pentagonal Patch Array Antenna for Breast Cancer Detection," 2016 IEEE Conference on Antenna Measurements \& Applications (CAMA), Oct 2016.

[9] O. O. Adedayo, M. M. Isa, and K. Budayawan, "Artificial Neural Network Model for Microwave Propagation in Water Melon," 2012 IEEE International Conference on Circuits and Systems (ICCAS), no. 6, pp. 147-149, 2012.

[10] O. O. Adedayo, M. M. Isa, A. C. Soh, and Z. Abbas, "Comparison of Feed Forward Neural Network Training Algorithms for Intelligent Modeling of Dielectric Properties of Oil Palm Fruitlets," Int. J. Eng. Adv. Technol., vol. 3, no. 3, pp. 38-42, 2014.

[11] D. A. Woten and M. El-Shenawee, "Improvement of Artificial Neural Network Detection of Breast Cancer using Broadband Dual Polarized Antenna," in IEEE Antennas and Propagation Society International Symposium, 2007, no. 1 , pp. 261-264.

[12] S. A. Alshehri and S. Khatun, "UWB Imaging for Breast Cancer Detection Using Neural Network," Prog. Electromagn. Res. C, vol. 7, pp. 79-93, 2009.

[13] S. E. Parveen, G. Sangeeta, and K. Dharminder, "Minimization of Error in Training a Neural Network Using Gradient Descent Method," Int. J. Tech. Res., vol. 1, no. 1, pp. 10-12, 2012.

[14] A. I. Imran and T. A. Elwi, "Engineering Science and Technology, an International Journal A cylindrical wideband slotted patch antenna loaded with Frequency Selective Surface for MRI applications," Int. J. Eng. Sci. Technol., vol. 20, pp. 990-996, 2017.

\section{BIOGRAPHIES OF AUTHORS}
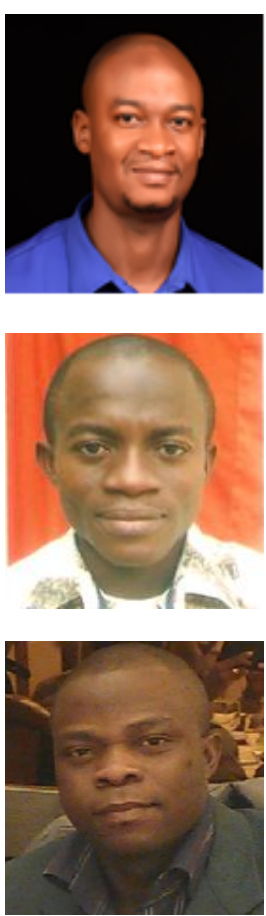

Ojo O. Adedayo graduated from the Department of Electronic and Electrical Engineering in Ladoke Akintola University of Technology (LAUTECH) Nigeria in 2008 where he received his B. Tech degree with honours. He obtained his Msc degree in Microelectronics from Universiti Putra Malaysia (UPM) in 2014. He is currently a lecturer at the department of Electronic Electrical and Computer Engineering, Afe Babalola University Ado Ekiti, Ekiti State Nigeria. He is currently pursuing a PhD degree at the Department of Electronic Electrical Engineering, Ekiti State University, Nigeria. His research interests include communication systems, microelectronics, soft computing and intelligent systems.

Engr. Dr. Moses Oluwafemi Onibonoje is a Senior Lecturer in the Department of Electrical/Electronics and Computer Engineering at Afe Babalola University Ado-Ekiti (ABUAD), Nigeria. He specializes in Control and Instrumentation Engineering. His research areas include Wireless Sensor Networks, Distributed Systems, Wireless Instrumentations, Optimization Methods, and Agro-Electro Instrumentations. Dr. Onibonoje holds a Ph.D. in Electronic and Electrical Engineering from Obafemi Awolowo University, Ile-Ife, Nigeria. He is COREN Registered and a Corporate Member of the Nigerian Society of Engineers.

Ogunlade Michael Adegoke received the Bachelor of Engineering degree in Electrical and Electronic Engineering from University of Ado Ekiti, Nigeria in 2008. He obtained the Master of Engineering degree in Signal and Information Processing from Tianjin University of Technology and Education, P. R. China. He is a lecturer and a researcher at Afe Babalola University, Ado Ekiti, Nigeria. He is currently pursuing $\mathrm{PhD}$ in Electrical and Electronic Engineering from Ekiti State University, Nigeria. He is a member of the Centre for Research in Electrical Communication (CRECO), Ekiti State University, Ado Ekiti, Nigeria. His research interests are in the area of wireless communication, power line communication, signal processing, Electronics and smart Antenna. 